\title{
Effects of Fruits Extracts of Three Medicinal Plants on the Blood Glucose Level of Glucose-induced Hyperglycemic and Normal Rabbit Models
}

\author{
Ikram Ilahi (Corresponding Author) \\ Assistant Professor, Department of Zoology, University of Malakand \\ Chakdara, Dir (L), Khyber Pakhtunkhwa, Pakistan \\ E-mail: ikramilahi@yahoo.com
}

Asghar Khan

Student, Department of Biotechnology, University of Malakand

Chakdara, Dir (L), Khyber Pakhtunkhwa, Pakistan

E-mail: asghar444@yahoo.com

\begin{abstract}
Ubaid Ullah
Student, Department of Biotechnology, University of Malakand Chakdara, Dir (L), Khyber Pakhtunkhwa, Pakistan E-mail: ubaid87_pk@yahoo.com
\end{abstract}

Imran Khan

Student, Department of Biotechnology, University of Malakand Chakdara, Dir (L), Khyber Pakhtunkhwa, Pakistan E-mail: 85@yahoo.com

Jawad Ali

Student, Department of Biotechnology, Faculty of Biological Sciences Quaid-i-Azam University, Islamabad, Pakistan.

E-mail: ajwdli@gmail.com 
Murad Khan

Lecture, Department of Biotechnology, University of Malakand

Chakdara, Dir (L), Khyber Pakhtunkhwa, Pakistan

E-mail: Pacifist88@yahoo.com

Received: June 17, 2012 Accepted: July 3, 2012

doi:10.5296/jbls.v3i1.1955 URL: http://dx.doi.org/10.5296/jbls.v3i1.1955

\begin{abstract}
s
The fruits of Pistacia integerrima (PI), Withania coagulans (WC) and Withania somnifera (WS) have been reported for their medicinal values. The aim of the present study was to compare the glucose lowering activities of the fruit extracts of these three medicinal plants in glucose induced non-diabetic hyperglycemic and normal rabbit models. During the first phase of experiments, the effects of oral administration of $70 \%$ methanol extract of each plant fruit (600 mg/kg body weight) and glibenclamide (5 mg/kg body weight) were studied on the glucose level of glucose induced hyperglycemic rabbits, while in the second phase of experiments, the effects of each fruit extract $(600 \mathrm{mg} / \mathrm{kg}$ body weight) and glibenclamide (5 $\mathrm{mg} / \mathrm{kg}$ body weight) were assessed on the glucose level of normal rabbits. Among the three fruit extracts, maximum reduction in the blood glucose level was caused by the PI extract (P $<0.05)$. The glucose lowering activity of the PI extract was greater than that of the standard, glibenclamide $(5 \mathrm{mg} / \mathrm{kg})$, during the first phase of experiments. However during the second phase of experiments the hypoglycemic effect of the PI extract was comparable to that of the standard, glibenclamide $(5 \mathrm{mg} / \mathrm{kg})$. In conclusion the present study reveals that the $70 \%$ methanol extract of Pistacia integerrima fruit can decrease glucose level significantly in glucose induced non-diabetic hyperglycemic and normal rabbit models.
\end{abstract}

Keywords: Pistacia integerrima, Withania coagulans, Withania somnifera, Glucose load, Glibenclamide

\title{
1. Introduction
}

Glucose is most important physiologically. Circulating glucose is derived from three sources: intestinal absorption during the fed state, glycogenolysis, and gluconeogenesis. Glycogenolysis and gluconeogenesis are partly under the control of glucagon, a hormone produced in the $\alpha$-cells of the pancreas (Aronoff et al., 2004). The blood glucose level of humans varies between 80 and $100 \mathrm{mg} / \mathrm{dl}$. Pancreas is the primary organ involved in sensing the organism's dietary and energetic states via glucose concentration in the blood and in response to elevated blood glucose, insulin is secreted (Edem, 2009). In conditions of high blood glucose level, more glucose enters into the $\beta$-cells of islet of Langerhans. More glucose is metabolized and as a result more ATPs are produced (Matschinsky, 1995; Maechler, 2006; 
Corkey, 2008). The increased concentration in intracellular ATP results in the closure of the ATP-sensitive $\mathrm{K}^{+}$channels $\left(\mathrm{K}_{\mathrm{ATP}}\right)$ and decreased outward $\mathrm{K}^{+}$transport. The voltage-gated $\mathrm{Ca}^{2+}$ channels become opened which results in the influx of extracellular $\mathrm{Ca}^{2+}$. The high concentration of intracellular $\mathrm{Ca}^{2+}$, activates protein motors and kinases, which then mediate exocytosis of insulin-containing vesicles that leads to the increased insulin and decreased blood glucose levels (Fridlyand et al., 2003).

Diabetes mellitus (DM) should be suspected if venous plasma glucose level drawn irrespective of when food was last eaten (a "random" sample of blood glucose) is unequivocally elevated (i.e., $\geq 200 \mathrm{mg} / \mathrm{dl}$ ), particularly in a patient who manifests the classic signs and symptoms of chronic hyperglycemia, polydipsia, polyuria, blurred vision, headaches, rapid weight loss, sometimes accompanied by nausea and vomiting (Marks et al., 1996).

Diabetes mellitus is characterized by high blood glucose level (Hyperglycemia). This is an important factor in the development and progression of diabetes and related complications (Luzi, 1998). More than 230 million people globally are affected with the disease (Arumugam et al., 2008). Management of diabetes is a huge burden. While therapeutic insulin production is not adequate to meet demands, the recombinant DNA approach to diabetes management has faced several problems. It is hypothesized that the ultimate therapy for type I and type II diabetes lies in the herbal approach (Arumugam et al., 2008).

Herbal anti- diabetic medicines are gaining more acceptances amongst diabetic patients because it is generally believed that herbal medicines lack side effects on the patients' health (Mahesh, 2010). More than 1000 plant species are being used for the treatment of diabetes (Marles \& Farnsworth, 1995). The anti-diabetic property of medicinal plants is attributed to the presence of some phytochemical ingredients. The medicinal plants which are used against diabetes, are rich in phenolic compounds, flavonoids, terpenoids, coumarins, and other constituents (Ji et al., 1998; Jung et al., 2006). Several species of anti-diabetic plants have been reported in the scientific and popular literature (Valianthan, 1998).

Pakistan is blessed with a variety of wild plants, which are being used for medicinal and aromatic purposes. Various preparations of medicinal plants are used for the treatments of diseases both at both community and user level. Many medicinal plants have still not been explored for their medicinal values (Ahmad \& Hussain, 2008). The plants Pistacia integerrima (Stew), Withania coagulans (Dunal) and Withania somnifera (Dunal) are among the medicinal plants found in Pakistan. The plant Pistacia integerrima is a medicinal plant (tree) of family Anacardiaceae, found in Eastern Afghanistan and some parts of Pakistan. The plants Withania coagulans and Withania somnifera are shrubs, belong to the old genus Withania of the family Solanaceae and found in Iran, Afghanistan, Pakistan and India (Yasin \& Nasir, 1985).

The fruit of Pistacia integerrima is known for its antimicrobial, antioxidant and hepatoprotective activities (Ahmad et al., 2008; Khan et al., 2008; Rahman et al., 2011;). Some plants of the family Anacardiaceae have been reported for their anti-hyperglycemic property. These include Mangifera indica, Spondias mangifera and Anacardium occidentale 
(Aderibigbe et al., 2001; Tedong et al., 2006; Acharyya et al., 2010). The fruits of Withania coagulans and Withania somnifera have been reported for their antidiabetic activities (Jaiswal et al., 2009; Hoda, et al., 2010).

In the present study, $70 \%$ methanol extracts of the fruits of Pistacia integerrima, Withania coagulans and Withania somnifera were prepared and tested for their effects on the level of blood glucose in glucose induced non-diabetic hyperglycemic rabbits and normal rabbits.

Aims and objectives: The present study was aimed to compare the anti-hyperglycemic potentials of the fruits of Pistacia integerrima, Withania coagulans and Withania somnifera in non- diabetic glucose induced hyperglycemic and normal rabbit models.

\section{Materials and Methods}

\subsection{Plant Material}

The dry fruits of Pistacia integerrima (Stew), Withania coagulans (Dunal) and Withania somnifera (Dunal) were purchased from the local market of Mingora Swat, Khyber Pakhtunkhwa. The fruits were botanically authenticated by Mr. Mahboob-ur-Rahman, Associated Professor, Department of Botany, Government Post Graduate Jehanzeb College, Swat, Khyber Pakhtunkhwa, Pakistan.

\subsection{Preparation of Crude Extract}

The clean and dried fruits of Pistacia integerrima, Withania coagulans and Withania somnifera were coarsely ground separately. Then 333.3 gram of PI fruit powder was soaked in $1666.6 \mathrm{ml}$ of $70 \%$ methanol, 182 gram of WC fruit powder in $600 \mathrm{ml}$ of $70 \%$ methanol and 112 gram of WS fruit powder in $400 \mathrm{ml}$ of $70 \%$ methanol for 3 days with occasional shaking. The soaked material was filtered through a muslin cloth. The filtrate of each plant was then separately evaporated on a rotary evaporator (Heidolph Laborta 4000 efficient) under reduced pressure. The extracts in concentrated solution forms were then transferred to beakers and placed in a well-ventilated room for evaporating the remaining solvent and finally the extracts of three plant fruits were obtained in dry form. The amount and percentage yield (w/w) of dry extract obtained from Pistacia integerrima was 115 gram (34.5\%), Withania coagulans 61.68 gram (33.51\%) and Withania somnifera 32.64 gram (29.14\%).

\subsection{Preliminary Phytochemical Screening}

A Preliminary phytochemical screening of $70 \%$ methanol extract of each plant extract was carried out by using standard procedures (Harborne, 1973).

\subsection{Experimental Design}

The experiments were performed in two phases. During the phase 1, the effects of plant extracts were studied on the glucose level of glucose induced hyperglycemic rabbits while in the second phase (Phase 2) of experiments the effects of plant extracts were assessed on the glucose level of normal rabbits. 


\section{Ml Macrothink}

Phase 1: Twenty five rabbits divided into five groups (5 rabbits each) were used in this experiment. The rabbits of each group were tagged with special color and figures on their ear pinnae. The detail is given below.

1. Control group, received glucose $500 \mathrm{mg} / \mathrm{Kg}$ body weight, and treated with $3 \mathrm{ml}$ of $2 \%$ dimethyl sulfoxide (DMSO) solution. This group was considered as hyperglycemic control group.

2. Standard group, received glucose $500 \mathrm{mg} / \mathrm{Kg}$ body weight and treated with glibenclamide $5 \mathrm{mg} / \mathrm{Kg}$ body weight, dissolved in $3 \mathrm{ml}$ of $2 \%$ dimethyl sulfoxide (DMSO)

3. PI ext group, received glucose $500 \mathrm{mg} / \mathrm{Kg}$ body weight and treated with Pistacia integerrima extract $600 \mathrm{mg} / \mathrm{Kg}$ body weight, dissolved in $3 \mathrm{ml}$ of $2 \%$ DMSO

4. WC ext group, received glucose $500 \mathrm{mg} / \mathrm{Kg}$ body weight and treated with Withania coagulans extract $600 \mathrm{mg} / \mathrm{Kg}$ body weight, dissolved in $3 \mathrm{ml}$ of $2 \%$ DMSO

5. WS group, received glucose $500 \mathrm{mg} / \mathrm{Kg}$ body weight and treated with Withania somnifera extract $600 \mathrm{mg} / \mathrm{Kg}$ body weight, dissolved in $3 \mathrm{ml}$ of $2 \%$ DMSO

\subsection{Procedure}

Pre-treatment $(0 \mathrm{hrs})$ blood glucose levels were measured after a 17 hours fast. Then the drug and plant extracts were administered orally by using oesophageal catheter. Then all the rabbits were orally administered with glucose at the dose of $2 \mathrm{~g} / \mathrm{kg}$ body weight after $30 \mathrm{~min}$ of extract and drugs administration. Blood glucose levels were measured through an electronic glucometer (Accu check Advantage $\Pi$, Roche Diagnostics, Germany) with a single drop of blood from marginal vein of ear rabbit after 1/2, 1, 2 and 3 hour of glucose load.

Phase 2: Twenty five rabbits divided into 5 groups (5 rabbits each) were used during this phase. This time the effects of plant extracts were studied on the glucose level of normal fasting rabbits, therefore the step of glucose load was skipped. The detail is given below.

1. Control group, treated with $3 \mathrm{ml}$ of $2 \%$ DMSO solution. This group was considered as normal control group

2. Standard group, treated with glibenclamide $5 \mathrm{mg} / \mathrm{Kg}$ body weight, dissolved in $3 \mathrm{ml}$ of $2 \%$ DMSO

3. PI group, treated with Pistacia integerrima extract $600 \mathrm{mg} / \mathrm{Kg}$ body weight, dissolved in $3 \mathrm{ml}$ of $2 \%$ DMSO

4. WC group, treated with Withania coagulans extract $600 \mathrm{mg} / \mathrm{Kg}$ body weight, dissolved in $3 \mathrm{ml}$ of $2 \%$ DMSO

5. WS group, treated with Withania somnifera extract $600 \mathrm{mg} / \mathrm{Kg}$ body weight, dissolved in $3 \mathrm{ml}$ of $2 \%$ DMSO 
Pre-treatment ( 0 hours) blood glucose levels were measured after a 17 hours fast. Then the drug and plant extracts were administered orally by using oesophageal catheter. Blood glucose levels were measured through an electronic glucometer (Accu check Advantage $\Pi$, Roche Diagnostics, Germany) with a single drop of blood from marginal vein of ear rabbit after 1/2, 1, 2 and 3 hour of drug and extract administration.

\subsection{Statistical Analysis}

Results were presented as mean + standard deviation. The means were compared by using Dunnett's Test of Post Hoc Multiple Comparisons in One Way Anova through SPSS 16 software for windows.

\section{Results and Discussion}

The preliminary phytochemical screening of each plant extract revealed the presence of tannins, saponins, glycosides, flavonoids and phenols. These ingredients have been reported for their anti-hyperglycemic activity (Sherman and Billing 1999; Sridhar et al., 2005; Anh and Kim, 2005; Zhou et al., 2009).

The effects of $70 \%$ methanol extracts of fruits of Pistacia integerrima (PI), Withania coagulans (WC) and Withania somnifera (WS) on the blood glucose level of glucose induced hyperglycemic rabbits studied during phase I are shown in table 1 . The table shows that at zero hour there was no significant difference in glucose levels of all groups ( $\mathrm{P}>0.05)$. After $1 / 2$ hour of glucose load, an increase in the glucose levels of all groups was observed which later on gradually declined. High amount of glucose in the blood stimulate insulin secretion, which enhance peripheral glucose consumption and controls the production of glucose through different mechanisms. The stimulation of insulin secretion by glucose results primarily from depolarization of $\beta$ cells plasma membrane (Meissner and Schmelz, 1974). When there occurs the depolarization of plasma membrane, the $\mathrm{ca}^{+2}$ starts entry to beta cells through voltage sensitive $\mathrm{ca}^{+2}$ channels (Satin \& cook, 1985). The increase in intracellular $\mathrm{Ca}^{2+}$ activates protein motors and kinases, which then mediate exocytosis of insulin-containing vesicles which lead to increased insulin and decreased blood glucose level (Fridlyand et al., 2003).

The rabbit of drug and the fruit extracts treated groups showed non-significant reduction $(\mathrm{P}>0.05)$ in glucose level when estimated after $1 / 2$ hour of glucose load. The Maximum decrease $(10 \%)$ in glucose level was observed in PI extract treated group. After $1^{\text {st }}$ hour of glucose load, the PI extract and the drug, glibenclamide caused $38 \%$ and $25.69 \%$ reduction in the blood glucose levels respectively. When the glucose levels of drug (119.70 \pm 7.32$)$ and the PI extract treated $(99.00 \pm 4.65)$ groups were compared to hyperglycemic control $(161.10+$ 11.03), the difference was significant $(\mathrm{P}<0.05)$. The mean glucose levels of WC extract $(145.35 \pm 8.10)$ and WS extract $(129.6 \pm 12.72)$ treated groups were also lower from the hyperglycemic control group, but the difference was non-significant $(P>0.05)$. After $2^{\text {nd }}$ hour of glucose load, a decrease in glucose levels of all groups was observed with time. A remarkable reduction in the blood glucose level was observed in the PI extract (37.66\%) and glibenclamide treated group $(28.74 \%)$. The difference in glucose levels from the control 
group was significant $(\mathrm{P}<0.05)$. After 3rd hour of glucose load, the glucose level of the drug, and each of the extract treated groups was significantly lower from hyperglycemic control group $(\mathrm{P}<0.05)$. Maximum reduction in blood glucose level was caused by glibenclamide (33.65\%) followed by PI extract (31.38\%), WS (24.76\%) and WC extract (23.08\%). In the extracts and drug treated groups, the glucose levels have not exceeded more than the control group, giving an indication regarding the supportive action of extract and drug in glucose utilization. The effect of glibenclamide on glucose tolerance has been attributed to enhanced activity of $\beta$ cells of pancreas resulting in secretion of large amount of insulin. The mechanism behind the anti-hyperglycemic activities of plant fruit extracts may involve insulin like effect by increasing peripheral glucose consumption or it may enhance the sensitivity of beta cells for glucose, resulting in an increased insulin release (Andrew, 2000).

The effects of $70 \%$ methanol extracts of fruits of Pistacia integerrima (PI), Withania coagulans (WC) and Withania somnifera (WS) on the blood glucose level of normal rabbits studied during phase II are shown in table 2. At zero hour there was no significant difference in glucose levels of all the groups $(\mathrm{P}>0.05)$. After $1 / 2$ and $1^{\text {st }}$ hour of drug and extract administration only glibenclamide caused significant reduction $(\mathrm{P}<0.05)$ in the blood glucose level of normal rabbits. After $2^{\text {nd }}$ and $3^{\text {rd }}$ hours of drug and extract administration, the drug and the PI extract caused significant $(\mathrm{P}<0.05)$ reduction in the blood glucose level. Glibenclamide caused $13.34 \%$ reduction after 2 nd hour and $20.32 \%$ reduction after $3^{\text {rd }}$ hour. The PI extract caused $10.37 \%$ reduction after 2 nd hour and $20.32 \%$ reduction after $3^{\text {rd }}$ hour of drug and extract administration.

The WC and WS extracts also caused reduction in the blood glucose level of normal rabbits but the difference from the control group was non-significant $(\mathrm{P}>0.05)$. During this study the drug glibenclamide and the PI extract resulted into a significant reduction of blood glucose level of normal rabbits. The hypoglycemic effects produced by the extract may be due to the increased insulin release resembling the mechanism of action of sulphonylurease (Miura et al., 2001; Okine et al., 2005).

The fruit of Pistacia integerrima is known for its antimicrobial, antioxidant and hepatoprotective activities (Ahmad et al., 2008; Khan et al., 2008; Rahman et al., 2011). Some plants of the family Anacardiaceae have been reported for their anti-hyperglycemic property. These include Mangifera indica, Spondias mangifera and Anacardium occidentale (Aderibigbe et al., 2001; Tedong et al., 2006; Acharyya et al., 2010). The fruits of Withania coagulans and Withania somnifera have been reported for their antidiabetic activities (Jaiswal et al., 2009; Hoda, et al., 2010).

In conclusion the present study reveals that the $70 \%$ methanol extract of Pistacia integerrima can decrease glucose level significantly in glucose induced non-diabetic hyperglycemic and normal rabbit models. 
Table 1. The effects of $70 \%$ methanol extracts of fruits of three medicinal plants on the glucose level $(\mathrm{mg} / \mathrm{dl})$ of non-diabetic glucose induced hyperglycemic rabbits at a dose of 600 $\mathrm{mg} / \mathrm{kg}$ body weight.

\begin{tabular}{|c|c|c|c|c|c|}
\hline Group & 0 hour & $1 / 2$ hour & 1 hour & 2 hours & 3 hours \\
\hline Control & $87.75 \pm 7.69$ & $139.50 \pm 8.28$ & $161.10+11.03$ & $138.3 \pm 9.9$ & $118.70 \pm 5.20$ \\
\hline Standard & $86.85 \pm 6.47$ & $\begin{array}{l}132.30 \pm 11.03 \\
(-5.16 \%)\end{array}$ & $\begin{array}{l}119.70 \pm 7.32 * \\
(-25.69 \%)\end{array}$ & $\begin{array}{c}98.55 \pm 7.25 * \\
(-28.74 \%) \\
\end{array}$ & $\begin{array}{c}78.75 \pm 8.2 * \\
(-33.65 \%)\end{array}$ \\
\hline PI ext & $91.80 \pm 8.18$ & $\begin{array}{l}125.55 \pm 13.70 \\
(-10 \%)\end{array}$ & $\begin{array}{l}99.00 \pm 4.65 * \\
(-38 \%)\end{array}$ & $\begin{array}{c}86.25 \pm 9.58 * \\
(-37.66 \%)\end{array}$ & $\begin{array}{l}81.45 \pm 7.72 * \\
(-31.38 \%)\end{array}$ \\
\hline WC ext & $91.80 \pm 8.18$ & $\begin{array}{c}140.4 \pm 15.29 \\
(+0.64 \%)\end{array}$ & $\begin{array}{c}145.35 \pm 8.10 \\
(-9.7 \%)\end{array}$ & $\begin{array}{c}125.8 \pm 6.6 \\
(-9.03 \%)\end{array}$ & $\begin{array}{l}91.3 \pm 6.1^{*} \\
(-23.08 \%)\end{array}$ \\
\hline WS ext & $94.5 \pm 9.32$ & $\begin{array}{l}138.6 \pm 12.02 \\
(-0.64 \%)\end{array}$ & $\begin{array}{c}129.6 \pm 12.72 \\
(-19.55 \%)\end{array}$ & $\begin{array}{l}114 \pm 13.18 \\
(-17.57 \%)\end{array}$ & $\begin{array}{c}89.3 \pm 7.14 * \\
(-24.76 \%)\end{array}$ \\
\hline
\end{tabular}

Standard-glibenclamide, PI ext- Pistacia integerrima extract, WC ext- Withania coagulans extract, WS extWithania somnifera extract, *- Indicates significant difference in the blood glucose level when compared to the hyperglycemic control group $(\mathrm{P}<0.05)$. Values in parentheses indicate percent increase $(+)$ or decrease $(-)$ in the blood glucose level of extract and drug treated animals from hyperglycemic control animals.

Table 2. Effects of $70 \%$ methanol extracts of fruits of three medicinal plants on the glucose level $(\mathrm{mg} / \mathrm{dl})$ of normal rabbits at a dose of $600 \mathrm{mg} / \mathrm{kg}$ body weight. $\mathrm{N}=5$

\begin{tabular}{|l|l|c|c|c|c|}
\hline Groups & $0 \mathrm{hr}$ & $1 / 2 \mathrm{hr}$ & $1 \mathrm{hr}$ & $2 \mathrm{hr}$ & $3 \mathrm{hr}$ \\
\hline Control & $102.7 \pm 2.52$ & $96.3+5.23$ & $92.5+2.8$ & $89.9+5.34$ & $84.5+2.1$ \\
\hline \multirow{2}{*}{ Glibenclamide } & $99.76+.74$ & $88.45+4.23 *$ & $(-12.16 \%)$ & $(-13.348 \%)$ & $(-20.320 \%)$ \\
\hline PI & $104.2+3.3$ & $(-6.521 \%)$ & $(-6.54 \%)$ & $(-10.37 \%)$ & $(-20.32 \%)$ \\
\hline WC & $98.02+2.76$ & $86.45+5.27$ & $80.57+4.32 *$ & $67.33+3.58 *$ \\
\hline WS & $101.4+3.40$ & $(-2.07 \%)$ & $(-3.17 \%)$ & $(-2.97 \%)$ & $(-5.37 \%)$ \\
\hline
\end{tabular}

PI-P. integerrima extract, WC- W.coagulans extract, WS- W.somnifera extract, *- Indicates significant difference in blood glucose level from normal control group $(\mathrm{P}<0.05)$, Values in parentheses indicate percent increase (+) or decrease (-) in blood glucose level of extract and drug treated animals from normal control animals after $1 / 2,1,2$ and $3^{\text {rd }}$ hours of glucose load. 


\section{References}

Acharyya1, S., Dashl, G. K., Mondal, S., \& Dash, S. K. (2010). Dash Studies on Hypoglycaemic Activity of the Different Extracts of Spondias mangifera willd. Journal of Pharmaceutical Science and Technology, 2(3), 184-190.

Aderibigbe, T. S., Emudianughe, \& Lawal, BAS. (2001). Evaluation of the Antidiabetic Action of Mangifera indica in Mice. Phytotherapy Research, 15, 456-458.

Ahmad, NS., Farman M., Najmi, MH., Mian, KB., \& Hasan, A. (2008). Pharmacological basis for use of Pistacia integerrima leaves in hyperuricemia and gout. Journal of Ethnopharmacology, 117(3), 478-482.

Ahmad, SS., \& Husain, SZ. (2008). Ethno medicinal survey of plants from Salt range (Kallar Kahar) of Pakistan. Pakistan Journal of Botany, 40(3), 1005-1011.

Andrew, JK. (2000). Diabetes. (pp. 1-9). New York: Churchill living stone.

Anh, M., \& Kim, JW. (2005). Identification and Qualification of steroidal saponins in polygonatum species by HPLC/ESI/MS. Archives of Pharmacal Research, 28(5), 592-597.

Arumugan, S., Kavimari, S., Kadalmani, B., AliAhmad, A.B., Akbarsha, M.A., \& Rao, M.A. (2008). Anti diabetic activity of Leaf and Callus extracts of Aegle marmelos in rabbit. Science Asia, 34, 317-331.

Aronoff, SL., Berkowitz, K., Shreiner, B., \& Want, L. (2004). Glucose Metabolism and Regulation: Beyond Insulin and Glucagon. Diabetes Spectrum, 17(3).

Arumugam, S., Kavimari, S., Kadalmani, B., Ahmad, ABA., Akbarsha, MA., \& Rao, MV. (2008). Anti-diabetic activity of Leaf and Callus extracts of Aegle marmelos in rabbit. Science Asia, 34, 317-331.

Ashcroft, FM., \& Rorsman, P. (1989). Electrophysiology of the $\beta$ cell. Progress in Biophyics and Molecular Biology, 54, 87-144.

Corkey, B. (2008). Metabolic regulation of insulin secretion. In Pancreatic Beta Cell in Health and Disease. (pp.53-74). Edited by Seino S. Japan: Springer.

Edem, DO. (2009). Hypoglycemic effects of ethanolic extract of Aligator pear seed (Persea Americana Mill) in rats. European Journal of Scientific Research, 33, 669-678.

Fridlyand, LE., Tamarina, N., \& Philipson, LH. (2003). Modeling of $\mathrm{Ca}^{+2}$ flux in pancreatic cells: role of the plasma membrane and intracellular stores. American Journal of Physiology Endocrinology and Metabolism, 285, E138-E154.

Harborne, JB. (1973). Phytochemical methods. (pp. 113). Chapman and Hall: London.

He, CN., Wang, VL., \& Guo, SX. (2005). Study on chemical constituents in herbs of Anoectochilus roxburghii II. China Journal of Chinese Materia Medica, 30, 761-776. 
Hoda, Q., Ahmad, S., Akhtar, M., \& Najme, A. (2010). Antihyperglycaemic and antihyperlipidaemic effect of poly-constituents, in aqueous and chloroform extracts, of Withania coagulans Dunal in experimental type 2 diabetes mellitus in rats. Human Experimental Toxicology, 29(8), 653-658.

Jaiswal, D., Rai, PR., \& Watal, G. (2009). Antidiabetic effect of Withania coagulans in experimental Rats. Indian Journal of Clinical Biochemistry, 24(1), 88-93.

Ji, HF., Li, XJ., \& Zhang, HY. (1998). Natural products and drug discovery. EMBO Reports, 10(3), 194-200.

Jung, M., Park, M., H-Ch., Lee, Kang, Y., Kang., \& Kim,SK. (2006). Antidiabetic agents from medicinal plants. Current Medicinal Chemistry, 13, 1203-1218.

Khan, MA., Jehanzeb., Shafiullah., Malik, SA., \& Shafi, M. (2008). Hepatoprotective effects of berberis lycium, galium aparine and pistacia integerrima in carbon tetrachloride (CCL4)-treated rats. Journal of Postgraduate Medical Institute, 22(2), 91-94.

Luzi, L. (1998). Pancreas transplantation and diabetic complications. The New England Journal of Medicines, 339, 115-117.

Maechler, P., Carobbio, S., \& Rubi, B. (2006). In beta-cells, mitochondria integrate and generate metabolic signals controlling insulin secretion. The International Journal Biochemistry and Cell Biol, 38, 696-709.

Mahesh, VA., Tasneem, AS., \& Chhaya, HG. (2010). Antidiabetic effects of yctanthes arbor-tristis (Oleaceae). An International Conference on Challenging and Emerging imensions in Medicinal/Herbal Plants and their Products: A Global Perspective; Chennai Trade Centre, Chennai, India.

Marks, DB., Marks, AD., \& Smith, CM. (1996). Basic Biochemistry: A clinical approach. (pp.472). Lippincott Williams \& Wilkins, Baltimore, Maryland USA.

Marles, RJ., \& Farnsworth, NR. (1995). Antidiabetic plants and their active constituents. Phytomedicine, 2, 137-189.

Matschinsky, FM. (1996). Banting Lecture 1996. A lesson in metabolic regulation inspired by the glucokinase glucose sensor paradigm. Diabetes, 45, 223-241.

Meissner, HP., \& Schmelz, H. (1974). Membrane potential of beta-cells in pancreatic islets. Pflügers Archiv European Journal of Physiology, 35, 1195-206.

Miura, T., Itoh, C., Iwamoto, N., Aato, M., Kawai, M., Park, SR., \& Suziki, I. (2001). Hypoglycemic activity of the fruit of the Momordica charantia in Type 2 diabetic mice. Journal of Nutritional Science and Vitaminology, 47, 340-344.

Okine, LKN., Nyarko, AK., Osei-Kwabena, N., \& Oppong. (2005). The antidiabetic activity of the herbal preparation ADD-199 in : a comparative study with two oral hypoglycaemic drugs. Journal of Ethnopharmacology, 97, 31-38. 


\section{Macrothink}

Rahman, S., Ismail, M., Muhammad, N., Ali1, F., Ahmad, K., Chishti,1., \& Imran, M. (2011). Evaluation of the stem bark of Pistacia Integerrima Stew ex Brandis for its antimicrobial and phytotoxic activities. African Journal of Pharmacy and Pharmacology, 5(8), 1170-1174.

Ravier, MA., \& Henquin C. (2002). Time and amplitude regulation of pulsatile insulin secretion by triggering and amplifying pathways in mouse islets. FEBS Letters, 530, 215-219.

Satin, LS., \& Cook, DL. (1985). Voltage-gated $\mathrm{Ca}^{+2 "}$ current in pancreatic $\beta$-cells. Pfluegers Archiv European Journal of Physiology, 404, 385-387.

Sherman, PW., \& Billing, J. (1999). Darwinian gastronomy: Whywe use spices. Bioscience, 49, 453-463.

Sridhar, SB., Sheetal, UD., Pai, MRSM., \& Shastri, MS. (2005). Preclinical evaluation of the antidiabetic effect of Eugenia jambolana seed powder in streptozotocindiabetic rats. Brazilian Journal of Medical and Biological Research, 38(3), 463-468.

Tedong., et al. (2006). Antihyperglycemic and renal protective activities of anacardium occidentale (anacardiaceae) leaves in streptozotocin induced diabetic rats. African Journal of Traditional, Complementary and Alternative Medicines, 3(1), 23 - 35.

Valianthan, MS. (1998). Healing plants. Current Science, 75, 1122-1126.

Yasin, J., \& Nasir, E. (1985). "Flora of Pakistan" Pakistan Agricultral Research Council. 168, 28-30.

Zhou1, T., Luo1,D., Li1, X., \& Luo, Y. (2009). Hypoglycemic and hypolipidemic effects of flavonoids from lotus (Nelumbo nuficera Gaertn) leaf in diabetic mice. Journal of Medicinal Plants Research, 3(4), 290-293.

\section{Copyright Disclaimer}

Copyright reserved by the author(s).

This article is an open-access article distributed under the terms and conditions of the Creative Commons Attribution license (http://creativecommons.org/licenses/by/3.0/). 